\title{
Apposition in English: A Linguistic Study Based on a Literary Corpus
}

\author{
María Dolores Gómez Penas \\ Universidad de Santiago de Compostela
}

Different approaches have been taken towards what apposition is, and as a consequence, divergences of opinion have emerged when deciding what is or is not an apposition. Diverse problems occur when we encounter structures that have a type of relation that, although different, shares the linguistic features that have been assigned to other relations within the linguistic system. In the studies on apposition that have been carried out, the following questions are asked: What kind of grammatical relation is there between the elements in apposition? Is it a relation of coordination or subordination? What kind of structures can be considered appositions? A lot of answers have been given to these questions. In the following we shall examine the criteria that have been used in order to define apposition, from the traditional ones to those used nowadays. Once we have described those criteria, we shall go on to analyse the syntactic, semantic and pragmatic characteristics of the examples in our literary corpus. The following corpus has been used in this research: A Good Man in Africa (GMA), by William Boyd; White Mischief (WM), by James Fox; Hotel du Lac (HL), by Anita Brooker; The Child in Time (ChT), by Ian McEwan; The Remains of the Day (RD), by Kazuo Ishiguro.

\section{II}

Traditional English grammars do not deal much with apposition. G. O. Curme affirms that there is a relation of subordination in the appositional structure and includes it in that part of his book that he dedicates to the subordinate elements in the clause. He names these elements modifiers. He uses the formal criterion of position in the clause to define apposition: "A noun which explains or characterizes another is placed alongside of it and from its position is accordingly called an appositive (i.e. placed alongside of): Smith, the banker" (129). 
The same formal criterion is found in Otto Jespersen's definition. Unlike Curme, he considers that apposition is a kind of coordination in which the absence of a firm cohesion between its elements is indicated by a pause and by intonation (13). These grammarians do not restrict apposition to noun phrases, they consider that linguistic units, such as the clause and the sentence, can also be elements of an appositional structure. Both, Curme and Jespersen, identify different kinds of apposition. And so, Curme mentions two types of apposition that he names loose apposition: "Where the appositive noun follows the governing noun in a rather loose connection ... Mary, the belle of the village" (129), and close apposition: "King George . . . the relation here between the appositive and its governing word is so close that they are in many cases felt as a compound" (131).

Neither Jespersen nor Curme clearly define what apposition is. The criteria they use to define it are not very precise and do not help us to establish the difference between apposition and other syntactic relations. R. W. Zandvoort does not study apposition thoroughly either. He gives a series of examples and just differentiates one from the other. He asserts that between "His father [or: a] renowed physician, died last week" and "his brother the explorer" there exists a difference "similar to that between continuative and restrictive clauses" (202), and he mentions subordination when comparing the examples "My brother Charles" and "King George." According to Zandvoort, a clear relation of subordination is not observed between the two elements in the structure "My brother Charles." However, he considers that in "King George" there is subordination of the element "King" with respect to the proper noun "George." This same idea will appear in later studies as we shall see in the following. For the American distributionalist Ch. F. Hockett appositives are a subtype of coordinate constructions. Both have in common the linguistic feature of having a double head. He postulates the following criteria for the appositives: "(1) the constitute must be endocentric; (2) the ICs must belong to the same major form class; (3) there must be no more justification for taking the first IC as attribute of the second as head than for the reverse; (4) the ICs must refer to the same entity" (101).

The second criterion, that the immediate constituents must belong to the same syntactic class, can be easily refuted. As we shall see in some examples from our corpus, both elements in apposition may belong to different syntactic classes. And so, one of them may be an adverbial phrase and the other a prepositional phrase. The third criterion is the one that makes apposition similar to coordination, because it considers that both elements are on the same level. However, instead of classifying the elements as heads, more in accordance with his definition of coordinate constructions, Hockett mentions the existence of an attributive relation between both elements, and so, he contradicts himself. As a consequence of this, his definition of apposition is not very clear. ${ }^{1}$ The fourth criterion, which establishes that both constituents may refer to the same entity, that is to say, that they must be coreferent, points out the main difference between apposition and coordination. In a coordinate construction the constituents are not coreferent, they lead us to different extralinguistic entities; while in an appositional construction, both elements refer to the same entity.

The combination of semantic and formal criteria is also present in H. Sopher's definition of apposition (401-12). This linguist, unlike Hockett, considers that the appositional elements may belong to different syntactic classes. He also considers that 
apposition differs from both subordination and coordination. However we can also observe a contradiction in this grammarian's definition, due to the fact that when he refers to the appositional elements, he speaks of head group and appositional group, which, in a way, implies subordination. For Sopher, the elements in apposition constitute a functional unit. Both are on the same grammatical level. If we omit one element and leave only the other element, the utterance in which they are inserted does not change. Both elements are interchangeable and there is a semantic relation of coreference between them. Therefore, when they are functioning as subject, they concord with the verb in singular. Lastly, we can use between both elements a connector such as that is, namely. In this way, the existing differences between apposition and other syntactic relations in the linguistic system are established. Sopher includes in his corpus examples of loose apposition and close apposition. However, like Zandvoort, he makes a difference between structures, such as my brother the explorer and others like King George the Fifth. He takes an important step forward by stating that the latter structure is not an apposition, but instead a kind of modification in which the first element, King, is the head, the second element, George, is the modifier of the head and the Fifth modifies both King and George. ${ }^{2}$ Close apposition has caused much more controversy than loose apposition when it comes to analysing it. Questions such as which of the two elements is the identifying one?, what kind of relation is there between the two elements?, are there two heads or a modifier and a head? have had different answers. So, E. Haugan in his study "On Resolving the Close Apposition" (165-70), unlike Sopher, considers that the first element is the modifier that helps to identify the second element. A different point of view is held by Hockett (102), who asserts that both elements may be heads and attributes, that is to say, the first element can identify the second, just as much as the second element can identify the first. The existing subordinate character between the members of a close apposition has led some experts not to consider these structures examples of apposition. So Burton-Roberts draws boundaries on the field of apposition, and considers that it exits only in those cases of loose apposition. We are in agreement with his opinion when he affirms that close apposition presents a structure of modifier followed by head, that is, we think that it has an adjectival purpose and so it is not apposition.

R. Quirk et al. put forward syntactic and semantic criteria in their definition of apposition. Their criteria, as we shall see in the following, are basically the same as those used by Sopher: "(1) each of the appositives can be omitted without affecting the acceptability of the sentence; (2) each fulfils the same syntactic function in the resultant sentences; (3) it can be assumed that there is no difference between the original sentence and either of the resultant sentences in extralinguistic reference" (1302).

Quirk et al. consider that apposition has similarities with both coordination and subordination. Even though these grammarians affirm that "[a]pposition resembles coordination in that not only do coordinate constructions also involve the linking of units of the same rank, but the central coordinators and and so may themselves occasionally be used as explicit markers of apposition" (1301-1302), later on they mention that in some cases, in the type of apposition they call partial (the financial expert Tom Timber), the subordinate character of one of the elements is highlighted due to the fact that it is the only one that can be omitted without altering the utterance (1305). 
Following Quirk et al.'s study, Ch. F. Meyer centres on apposition, basing his remarks on syntactic, semantic and pragmatic characteristics. This linguist, like Quirk et al., includes more semantic relations between the elements in apposition. Semantically, that relation, according to Meyer, may be co-referential ("my father, John"), hyponymous ("a tree, an oak tree"), synonymous ("a priest, a man of the clergy") and attributive ("my sister, a tax accountant") (103). The criteria established by Meyer to define apposition are the following: "semantic constraint: U1 and U2 are coreferential, hyponymous, synonymous, or attributively related; pragmatic constraint: $\mathrm{U} 2$ suplies new information about $\mathrm{U} 1$; syntactic constraint: either $\mathrm{U} 1$ and $\mathrm{U} 2$ are juxtaposed or they must be able to be juxtaposed without the resulting sentence becoming unacceptable" (120).

Using these criteria an ample number of linguistic structures are considered to be appositions. We have used Quirk et al.'s criteria to form our corpus because they were more suitable for it. But, we have restricted the corpus we are going to analyse to loose apposition only, because, as we have previously mentioned, we believe that a structure in a close apposition has an adjectival character and so, it cannot be considered an apposition.

III

\section{Syntactic characteristics}

(a) Syntactic class of the elements in an appositive relation

It has been repeatedly pointed out that an appositive relation may be found in linguistic units higher than the phrase. However, grammarians are in agreement that it is a type of relation that takes place mainly between phrases. And they make their definition even more specific by stating that it is to be found for the most part in noun phrases. After analysing our corpus we agree with this, noun phrases are much more common in our corpus than other grammatical units. Those noun phrases may have a common noun (example 1), a proper noun (example 2), or a personal pronoun (example 3), demonstrative (example 4) or indefinite (example 5) as heads:

1. Denzil Jones, the accountant, poked his head round it. (GMA 14)

2. Erroll's daughter, Diana ... had come to England to live with her aunt. (WM 98)

3. The sort of woman she, Mrs. Pursey, should not be asked to admit into her presence. (HL 84)

4. This-Innocence-was the first dead person he had ever encountered. (GMA 73)

5. Everything about her seemed exaggerated: her height, the length of her extraordinary fingers.... ( $H L$ 70)

Table $\mathbf{A}$ on the next page shows the different syntactic classes that the elements in apposition present in our corpus. As one can see, the appositive relation is found in $95 \%$ of the examples of noun phrases and only $5 \%$ in other types of phrases. We can also observe that the elements in an appositive relation do not have to belong neccesarily to the 
same syntactic class, although in most cases they do. We shall quote some of the examples in our corpus:

6. She behaved well ... : quietly, politely, venturing little. (HL 85)

7. He was getting too large: fifteen and a half stone at the last weigh-in. (GMA 42)

8. He was still there, in the same old flat, that Julie had gone. (ChT 136)

Syntactic Class

\begin{tabular}{|c|c|c|c|c|c|c|c|}
\hline & GMA & WM & HL & $\mathrm{ChT}$ & RD & Total & $\%$ \\
\hline$N P+N P$ & 71 & 355 & 58 & 80 & 83 & 647 & $95 \%$ \\
\hline $\mathrm{NP}+$ PreP & & 1 & & & 1 & & \\
\hline NP + Clause & 2 & 5 & 2 & 1 & 1 & 11 & \\
\hline AdjP + AdjP & 1 & & & & & 1 & \\
\hline AdjP + NP & 1 & 1 & & & 1 & 3 & \\
\hline$A d v P+A d v P$ & & & 1 & & & 1 & \\
\hline AdvP + PreP & & 1 & & 1 & & 2 & \\
\hline PreP + PreP & & 4 & & & & 4 & \\
\hline PreP + AdverbP & & & & & 1 & 1 & \\
\hline Clause + NP & 2 & 2 & & 2 & 1 & 7 & \\
\hline Total & 77 & 368 & 62 & 85 & 86 & 678 & \\
\hline $\begin{array}{l}\text { NP = Noun Phrase } \\
\text { PrepP = Prepositional Ph } \\
\text { AdjP = Adjective Phrase } \\
\text { AdvP = Adverb Phrase }\end{array}$ & & & . & & & & Table A \\
\hline
\end{tabular}

Syntactically, the structures which the elements in apposition present may be simple or complex. The head of the noun phrase may stand alone, as in examples (2) and (4) or accompanied by other elements, such as determiners and modifiers, as in the following example:

9. His wife, a tiny smiling woman with a creamy caramel skin and huge dangling earrings, was in a lacy blouse.... (GMA 238)

One striking formal characteristic of the second appositive element is the absence of a determiner before the common noun. There are twenty-six examples in our corpus in which the common noun in the second element is not preceded by a determiner. This lack of a determiner is commented on by Quirk et al.: "In a type of partial apposition expressing attribution (particularly a unique role), an article (definite or indefinite) is absent from the defining appositive" (1313). In all the examples of our corpus, a semantic relation of attribution exists between the two elements. The first element is generally a proper noun and the second is a conmon noun in singular. In most of the examples (19 out of 26), the 
second element is a noun which indicates blood ties and postmodification is a common characteristic in all of them, as example (10) illustrates:

10. Michael Lafone, a fierce womanizer with an eyeglass, who was briefly and disastrously married in Kenya to E. Byng, daughter of the Earl of Stratford. (WM 33)

The complexity of the appositive elements is not only because there is an accumulation of determiners, premodifiers and postmodifiers but also because they consist of two or more noun phrases that are juxtaposed (example 11) or coordinated (example 12). In other cases that complexity is due to the fact that there is an accumulation of appositions (example 13):

11. His wife laughed scornfully, knowing him to be burdened with responsabilities - houses, children, professional standing that he could not shed. (HL 85) 12. And there were two other guests for lunch: Juanita Carberry, Junes fifteen year old step daughter, and her governor, Isabel Rutt. (WM 88)

13. He linked the name with the person who was Fanshave's wife: Mrs. Chloe Fanshawe, wife to the Deputy. (GMA 29)

In (12), the second element is formed by two noun phrases joined by the conjunction and; at the same time, each of them forms an apposition with the noun phrase which immediately follows it, that is, we have an apposition within an apposition. In (13), the third element is in apposition with the second element and both the second and the third are in apposition with the first element. However, we have to mention that these complex appositions are not very common in our corpus. The author, by using an accumulation of appositions, gives a more complete description of the character in a concise, brief and almost telegraphic way.

\section{(b) Syntactic function of the elements in an appositive relation}

The appositive elements in our corpus have the following functions in the clause in which they are inserted: subject, direct object, indirect object, subject complement, object complement, prepositional object and adverbial. Table B shows the percentages of these functions.

Syntactic Function

\begin{tabular}{lrrrrrrr}
\hline & GMA & WM & HL & ChT & RD & Total & $\%$ \\
non-existential subject & 19 & 136 & 28 & 25 & 23 & 228 & $33 \%$ \\
existential subject & 1 & 7 & 2 & 5 & & 15 & $2 \%$ \\
direct object & 14 & 56 & 11 & 17 & 21 & 119 & $17 \%$ \\
indirect object & & 3 & & & & 3 & $0.45 \%$ \\
prepositional object & 23 & 134 & 19 & 28 & 31 & 235 & $35 \%$
\end{tabular}


subject complement

object complement

adverbial

Total
18

1

76

$\begin{array}{rr}30 & 1 \\ 2 & 1 \\ 364 & 62\end{array}$

6

2

83

$\begin{array}{rr}9 & 64 \\ & 1 \\ 1 & 6 \\ 85 & 671\end{array}$

671
$9 \%$
$0.15 \%$
$0.90 \%$

Table B

Both elements in apposition have always the same function, that is to say, they form a functional unit. As has been suggested before, the two appositive elements are generally noun phrases, and so, as Meyer states (Apposition in Contemporary English 34-35), their functions are, in most cases the same as those of noun phrases. Table B shows that the functions of existential subject together with those of prepositional object, direct object, indirect object, subject complement, object complement and adverbial, which promote end-weight, are more numerous, $66 \%$ to be more precise, than the function of nonexistential subject. So the two appositive elements are in most cases placed after the verb phrase of the clause in which they are inserted. Therefore, we agree with Meyer when he says that: "In addition to having functions associated with noun phrases, appositions had functions associated with positions in the sentence, clause or phrase that promoted Quirk et al's principle of end-weight" (Apposition in Contemporary English 35). According to that principle, complex linguistic units which the speaker or the writer want to emphasize are placed towards the end of the utterance. We shall quote some of the examples in our corpus, indicating the function of the apposition:

14. Mrs. Woodhouse had moved to Hastings in the mid- 1960s and met there, in the Queen's Hotel, on a windy day in late July. (WM 230). Adverbial.

15. Now her boss was Mr. Middlebrook, a tall, thin man.... (ChT 167). Subject complement.

16. . . . the little man was hopelessly inept, had never got to grips with the English language, and was cordially detested by Moses, the Morgan's cook. (GMA 64). Prepositional object.

17... . Morgan had bought their priciest wine, a sweetish highly scented Piesporter.... (GMA 105). Direct object.

18. For there was love there, love between mother and daughter. ... (HL 48). Existential subject.

19. Harriet, the life-loving young divorcee, had first met Broughton at Highclere.... (WM 61). Non-existential subject.

In our corpus, the number of appositions which function as non-existential subject, a function which does not promote end-weight, is high, 228 examples to be precise. Of those, only $9 \%$ are placed after the verb. Table $C$ on the next page shows the order of the apposition and the verbal predicate in the clause in which they are inserted. As we can observe, $82 \%$ of the examples are placed after the verb and are juxtaposed (example 20):

20. And my kind hosts, Mr. and Mrs. Taylor, would never, I am certain, have knowingly put me through what I have just endured. ( $R D 180)$ 
Only $9 \%$ of the examples are placed after the verb, as we have mentioned before. This inverse order of Verb + Subject is found in those cases where the subject is a long sequence and the predicate is short (example 21), or in a direct language clause (example 22), or in structures which are mainly found in an informal register (example 23):

21. Among them was Jack Soames, an old Etonian who was thirty-two when he arrived in 1920. (WM 22)

22. He was the most boring man in the world, said his neighbour on lake Naivasha, a trophy-hunting Austrian called Baron Knapitsch. (WM 246)

23. Here was Stephen now, a foot soldier in this army of experts.... (ChT 81)

The appositive elements are, in most cases, placed one after the other;however, the continuity of the elements is interrupted by the verbal predicate in some examples, as can be observed in Table C. In other examples, the discontinuity is due to the fact that an apposition marker, such as, that is, namely, or a parenthetical phrase or clause is placed between both elements. Table $\mathrm{D}$ shows the existing proportion between juxtaposed and unjuxtaposed elements in our corpus.

Order of the appositive elements in subject position

\begin{tabular}{lrrrrrrr}
\hline & GMA & WM & HL & ChT & RD & Total & $\%$ \\
1st el. + 2nd el. + VP & 13 & 116 & 24 & 15 & 19 & 187 & $82 \%$ \\
1st el. + VP + 2nd el. & 3 & 6 & 3 & 5 & 3 & 20 & $8 \%$ \\
VP + 1st el. + 2nd el. & 3 & 13 & & 5 & & 21 & $9 \%$ \\
Total & 19 & 135 & 27 & 25 & 22 & 228 & \\
el. = element & & & & & & & \\
VP = verbal predicate & & & & & & & \\
\end{tabular}

Juxtaposed and unjuxtaposed elements in our corpus

\begin{tabular}{lrrrrrrr}
\hline & GMA & WM & HL & ChT & RD & Total & $\%$ \\
Juxtaposed & 68 & 355 & 53 & 74 & 79 & 629 & $92 \%$ \\
Unjuxtaposed & 9 & 13 & 9 & 11 & 7 & 49 & $7 \%$ \\
Total & 77 & 368 & 62 & 85 & 86 & 678 &
\end{tabular}

Table D

As can be seen, in the majority of cases the appositive elements are juxtaposed, in $92 \%$ of the examples. In other cases, all the predicate or part of the predicate is placed between both elements. In this way, the continuity of the apposition is broken. This discontinuity 
takes place when the apposition, functioning as a subject, is a long sequence and the predicate is very short (example 24):

24. The requirements were simple: an unobstructed view of a changing landscape, however dull, and freedom from the breath of other passengers, their body warmth, sandwiches and limbs. (ChT 50)

We agree with Meyer when he says that this order of the constituents is based on the principle of end-weight. As Quirk et al. assert, some elements may be interposed in a noun phrase "to achieve a stylistically well-balanced sentence in accordance with the norms of English structure" (1398). That discontinuity is also due to what Quirk et al. name endfocus. Thus, the second element is given more importance because it is placed at the end of the clause. Therefore, in example (24), the second element is emphasized not only because the adverb specially is used, but also because the second element women is placed after the predicate.

25. People love this one, especially women. (HL 27)

In some examples there is only one order possible in the structure of the utterance. In example (26), the two elements may not be juxtaposed:

26. The car keys were in his hand, his wallet was smug in his inside pocket-the equipment of audulthood. (ChT 121)

However, for the second element to be given more importance than the others, it does not necessarily have to go in final position in the clause. With a simple change in the order of the elements the author emphasizes the second element more, as in example (27):

27. Had she said that he was cross and peevish on the night of the murder, while they were drinking brandy-June and he-in the Muthaiga bar? (WM 90-91)

\section{Semantic and pragmatic characteristics}

The semantic classifications of apposition made by Quirk et al. ${ }^{3}$ and Meyer ${ }^{4}$ do not differ greatly. In both of them the specification of the elements is mentioned, that is to say, when one of the elements is more, less or as specific as the other. We have found that Meyer's classification is more suitable for the analysis of our corpus and that is why we employ it in this paper. Table $\mathrm{E}$ on the next page shows the different semantic classes of apposition in our corpus.

As Table E illustrates, the highest percentage of examples, $50 \%$ to be more precise, are those appositions in which the second element is more specific than the first. We have to point out in the more specific group the widespread use of examples belonging to the semantic classes of appellation (example 28) and identification (example 29): 
28. My elder brother, Leonard, was killed during the Southern African War while I was still a boy. $(R D 40)$

29. Morgan realized, with some alarm, as he approached that this-Innocence was the first dead person he had ever encountered... (GMA 73)

In example (28) the two elements refer to the same person. There is a semantic relation of coreference, but the second element, Leonard, is more specific than the first. The proper noun specifies the name of my elder brother. As Quirk et al. say, it is a naming relation (1309). In example (29), the second element, Innocence, identifies the first, this, a demonstrative pronoun. Therefore, the second element is more specific than the first. Less numerous in our corpus are the examples belonging to the semantic classes of particularization (examples 30 and 31) and exemplification (example 32). The referents are not the same and in both classes an element is included within the other:

30. It was noticeable, moreover, that the Wakefields-Mrs. Wakefield in particular-were themselves by no means ignorant of the traditions in our country ... (RD 122-23)

31. It does not seem to have occurred to anybody that Joss Erroll might have been murdered by $a$ woman - a woman who used a gun in the Gare du Nord and wounded the man she married later. (WM 219)

32. Morris called only eight witnesses, including Broughton and the loyal Major Pembroke against the prosecution's twenty. (WM 108)

In (30) the Wakefields refer to both, the husband and his wife, and Mrs. Wakefield stands out by being used as the second element in the appositive structure. In (31) the two elements are in a hyponymous relation; in this case, unlike the other examples of this class, the head of the second element is the same lexeme as the head of the first element and, in our corpus, it is always accompanied by postmodifiers. In this way, a certain part or a characteristic of something/somebody just mentioned is made to stand out by the author. As Quirk et al. observe: "the intention may be rhetorical to provide a climatic effect by repetition and expansion of the first noun phrase" (1312). Like Quirk et al., Joan N. Bitea in her study "An Attempt at Defining Apposition in Modern English" also mentions this effect of apposition: "Rhetorical effects are also obtained by means of developing appositions: appositions which constitute both formally and semantically developments of their correlatives" (472). In example (32), the second element, "including Broughton and the loyal Major Pembroke," specifies some of the witnesses referred to in the first element, and so, it is more specific.

Semantic classes of apposition

More specific

GMA WM HL ChT RD Total $\%$

a) Appellation

$11 \quad 114$

114
55

13

10

10

158

$23 \%$

b) Identification

21

11

39

20

146

$21 \%$

c) Particularization

3

14

32

$4.7 \%$ 
d) Exemplification

Total $a+b+c+d$

Less specific

a) Characterization

Equally specific

a) Paraphrase

b) Reorientation

Total $a+b$
6
$32 \quad 180$

44

188

16

33

39

320

$47 \%$

$\begin{array}{rrrr} & 1 & 1 & 0.15 \% \\ 1 & 11 & 12 & 1 \% \\ 1 & 12 & 13 & 3 \%\end{array}$

Table E

In $47 \%$ of the examples, those belonging to the semantic class named characterization, the second element is less specific than the first, it describes a particularity of it (example 33):

33. When the letter arrived it was not from Charles Darke, the young senior editor profiled in the Sunday newspaper.... (ChT 29)

In the preceding example, the second element is a noun phrase which attributes a characteristic to the first element. And so, the relation between them is an attributive relation, the first element is a proper noun and is more specific than the second.

We have not found a lot of examples in our corpus in which the first element is as specific as the second element. As Table E indicates, we have only found examples belonging to the semantic classes of paraphrase (example 34) and reorientation (example 35):

34. The here and now, the quotidian, was beginning to acquire substance. (HL 37) 35. Mrs. Pusey, that pinnacle of feminine chic, that arbiter of taste, that relentless seeker after luxury foods, that charmer of multitudes, is seventy-nine! (HL 103)

In (34) the second element paraphrases the first. In (35) the second element describes several characteristics of Mrs. Pusey, the author refers to Mrs. Pusey again by using all those noun phrases, both elements refer to the same person, there is a semantic relation of coreference.

By using apposition the author foregrounds a certain aspect of the discourse, an aspect which has great importance in the interchange between the interlocutors. Pragmatically, the second element is generally an explanation of the first. It usually adds information that the speaker or narrator consider necessary to clarify what they have previously expounded. In some cases it avoids possible ambiguity. E. Koktova's words summarize some psychological properties of apposition: "From a psychological viewpoint, apposition (or, more exactly, the apposed elements) should be viewed as the speaker's commentary, as an afterthought, as an implicit predication, or as a secondary information, of a sentence-simply as 
a message which deflects from the mainstream of communication and which should be kept distinct from the proper assertion (main information) of a sentence" (40-41).

In our literary corpus, we have observed that the number of appositions in the dialogues is noticiably less than in the rest of the text, we have found only 17 examples. This is due to the fact that, in a dialogue, the information that the second appositive element gives about the first is no necessary because the interlocutors are generally aware of information implicit in the discourse. As we have previously mentioned, in our corpus apposition is used in most cases to name, identify and characterize something or somebody. In this last case, although the author uses a proper noun and identifies the character totally, he still thinks it necessary to make it more palpable. In this way, the reader is aware of exactly who the author is referring to. Among the literary works which make up our corpus, we have to point out in particular J. Fox's Who Killed John Erroll? White Mischief, because of the high number of appositions found there, 368 examples out of the total 678 examples that we have analysed. In our opinion, there are two main reasons for the use of apposition in this literary work. On the one hand, the narrator is just a kind of detective who reports a murder that took place in Africa. As a result, the narration resembles press writing and is, as a consequence, different from the other works in our corpus. In press reportage appositions are much more common, as Meyer states (Apposition in Contemporary English 100), than in other genres, because information in a newspaper has to be explained very accurately as the reader and the journalist do not share much knowledge about what is being reported. On the other hand, J. Fox gives life to a series of people, the majority belonging to the same community who, in one way or another, have been involved in the murder. The number of characters is so high and their names are changed so often throughout the book that the reader could have difficulty in following the plot. The fact that the author includes a list with the names of the characters at the end of the book indicates that he is conscious of such a difficulty. By adding information through the use of the second appositive element, the author always makes clear who exactly he is referring to. Consequently, in this work we also find a lot of appositions with more than one element (examples 34 and 35):

34. One of the few women who didn't see him as the epitome of sexual attraction was Dushka Repton, a Russian beauty married to a settler farmer, Gruy Repton, who was insanely jealous of his wife and eventually died of drink. (WM 36)

35.Lady Altrincham (then Lady Grigg, wife of the Governor) put Idina on her black list. (WM 31)

\section{IV}

\section{Conclusions}

In the preceding pages we have carried out a descriptive analysis of apposition based on a literary corpus from a syntactic, semantic and pragmatic point of view. We have analysed the characteristics which differentiate apposition from other relations within the 
linguistic system, and we have observed that it is a type of relation which is mainly found among juxtaposed noun phrases. These noun phrases have the same function within the clause in which they are inserted. It is mainly used to characterize, name and identify characters and everything the author considers necessary. In this way, the author transmits information which helps him not only to give detailed yet concise descriptions, but also, in some cases, to help the reader to follow the story.

\section{Notes}

1. N. Burton-Roberts (393) mentions this contradiction in his analysis of apposition.

2. Donald W. Lec (268-75) analyses these structures in the same way as Sopher.

3. Quirk et al. (1308) classify apposition in the following semantic classes: most appositive (a) equivalence: (ai) appellation: that is (to say); (aii) identification: namely; (aiii) designation: that is to say; (aiv) reformulation: in other words; (b) attribution (non-restrictive relative clause); (c) inclusion: (ci) exemplification: for example, say; (cii) particularization: especially.

4. Ch. F. Meyer (74) classifies apposition in the following semantic classes: more specific: identification, appellation, particularization, exemplification; less specific: characterization; equally specific: paraphrase, reorientation, self-correction.

\section{Works Cited}

Bitea, Joan N. "An Attempt at Defining Apposition in Modern English." Revue Romaine de Linguistique 13.4 (1977): 453-77.

Boyd, William. A Good Man in Africa. Hardmondsworth: Penguin, 1981.

Brooker, Anita. Hotel du Lac. London: Triad Grafton Books, 1985.

Burton-Roberts, N. "Nominal Apposition." Foundations of Language 13.3 (1975): 391-19.

Curme, G. O. English Grammar. New York: Barnes and Noble, 1947.

Fox, James. White Mischief. Hardmondsworth: Penguin, 1982.

Haugan, E. "On Resolving the Close Apposition." American Speech 28.3 (1953): 165-70

Hockett, Ch. F. “Attribution and Apposition." American Speech 30.2 (1955): 99-102.

Ishiguro, Kazuo. The Remains of the Day. London: Faber and Faber, 1989.

Jespersen, Otto. Analytic Syntax. New York: Holt, Rinehart and Winston, 1969.

Koktova, Eva. "Apposition as a Pragmatic Phenomenon in a Functional Description." UEA Papers in Linguistics 23 (1985): 39-79.

McEwan, Ian. The Child in Time. London: Pan Books, 1988.

Meyer, Ch. F. “Apposition in English.” Journal of English Linguistics 20.1 (1987): 101-21. . Apposition in Contemporary English. Cambridge: Cambridge UP, 1992.

Quirk, Randolph, et al. A Comprehensive Grammar of the English Language. London: Longman, 1985.

Sopher, H. “Apposition." English Studies 52 (1972): 401-12.

Zandvoort, R. W. A Handbook of English Grammar. London: Longman, 1977. 